http://jmscr.igmpublication.org/home/

ISSN (e)-2347-176x ISSN (p) 2455-0450

crossref DOI: https://dx.doi.org/10.18535/jmscr/v7i7.111

Journal Of Medical Science And Clinical Research

IGM Publication

An official Publication of IGM Publication

\title{
A Comparative Study on Efficacy of HSG and Hysteroscopy in Diagnosing Tubal Block in Primary Infertility
}

\author{
Authors \\ Dr S.P. Aiswarya.,MBBS.MS (Obg) ${ }^{1}$, Dr Sundar Narayanan., MBBS. MD² \\ ${ }^{1}$ Endogynaecology Fellowship Resident, Siva hospital \\ ${ }^{2}$ Professor of Endogynaecology Department, Siva Hospital
}

\begin{abstract}
This study was aimed to find the efficacy of the modern hystero-laproscopy (DHL) over hysterosalphingogram (HSG) in primary infertility patients with bilateral tubal block.

Materials and Methods: this study was conducted at Sudha Sunder hospital, Kanyakumari, India from Jan 2019 to June 2019 after institutional ethical clearance. Women with primary infertility who were diagnosed with bilateral tubal block through hystero-salphingogram were taken into this study. Hysteroscopy was done in these patients and the findings were noted, treated accordingly.

Results: 57primary infertility patients who were diagnosed to have bilateral tubal block in HSG were taken for the study. DLH was done for all these patients. Of these 33 patients had bilateral tubal block and the same was recanalized in all except one patient due to PID, 7 patients had unilateral tubal block and all were recanalized except one also due to PID and the rest 17 patients had a normal study.

Conclusion: this study suggests the superiority of diagnostic hystero laparoscopy over the routine, cost effective HSG which can be done as an OP procedure. Though DHL is an invasive procedure, it is 100\% accurate compared to HSG that's only $60 \%$ reliable in case of diagnosing tubal blocks.
\end{abstract}

\section{Introduction}

The WHO has defined infertility as "a disease of the reproductive system defined by the failure to achieve a clinical pregnancy after 12 months or more of regular unprotected sexual intercourse."(1) Infertility is one of the most prevalent problems as a result of rapid urbanization and related family nuclearization associated with it. In the Indian population around 15 percent of couples around are deemed infertile. The stigmatization it carries in India makes it a dreadful one. ${ }^{(2)}$

The basic workup while investigating the infertile couple after counselling along with history taking includes semen analysis, tests for ovulation and tests for tubal patency. ${ }^{(3)}$
Hysterosalpingography (HSG) plays an important diagnostic role in finding the cause of infertility and in deciding the line of management. HSG is a simple, safe, and minimally invasive radiologic procedure to visualize uterine cavity and tubes after contrast enhancement. ${ }^{(4)}$ Though pelvic sonography and HSG are good enough for excluding gross intrauterine pathology, subtle changes which influences fertility, can be missed. These subtle changes are better picked up on magnification with hysteroscopy. ${ }^{(5)}$ Hysteroscopy involves inspection of uterine cavity and the cornual ends of the fallopian tube with an endoscope inserted through the cervix, this when 
combined with laparoscopy yields more beneficial results. ${ }^{(1,6)}$

Debate still continues on the role of HSG and hysteron- laparoscopy in diagnosing the causes of infertility. This study is designed to compare the diagnostic value of HSG with hysteroscopy in the assessment of bilateral tubal block.

\section{Aim}

This study was aimed to find the efficacy of the modern hystero-laproscopy (DHL) over hysterosalphingogram (HSG) in primary infertility patients with bilateral tubal block.

\section{Materials and Methods}

This study was conducted at Sudha Sunder hospital, Kanyakumari, India from Jan 2019 to June 2019 after institutional ethical clearance.

Patient who consented were only included in this study along with primary infertility patients without hormonal changes, healthy partners and patients who were diagnosed with bilateral tubal blocks through HSG.

Patients who did not consent were excluded along with patients who had hormonal problems and unhealthy partners.

Women with primary infertility who were diagnosed with bilateral tubal block through hystero-salphingogram were taken into this study. Through history and physical examination was done in these patients along with blood investigations.

Hysteroscopy was done in these patients and the findings were noted, treated accordingly.

\section{Results}

57 primary infertility patients who were diagnosed to have bilateral tubal block in HSG were taken for the study.

These patients had no hormonal imbalance and had healthy partners who had been tested for the same.

\section{DLH results:}

Of these 33 patients had bilateral tubal block and the same was recanalized in all except one patient due to PID, 7 patients had unilateral tubal block and all were recanalized except one also due to PID and the rest 17 patients had a normal study.

\section{no of patients}

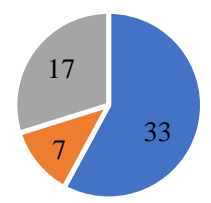

- Bilateral tubal block $\quad$ unilateral tubal block " normal study

This implies that HSG has $29 \%$ false positive result. HSG yields only $57 \%$ true positive results. Of the 40 patients with tubal block diagnosed in DHL, recanalization was done for all patients. Only 2 among them was a failure. Which suggests only a $5 \%$ failure rate in therapeutic abilities of DHL. These two patients had PID which was the reason for failure for recanalization.

Post-operatively was uneventful for all patients. Only 1 patient had mild discomfort post-surgery, others recovered uneventfully.

\section{Discussion}

Infertility is a serious problem to the couple and brings about family unhappiness and mental trauma and is a matter of financial burden. Among females, the most common cause is tuboperitoneal pathology accounting for $30 \%-35 \%$ cases followed by ovulatory dysfunction (20\%-30\% cases) and uterine pathology (15\% cases). The gold standard for evaluating tuboperitoneal pathology is laparoscopy. ${ }^{(1,4)}$ We found that HSG is only about $60 \%$ effective in diagnosing tubal blocks in comparison to hystero-laparoscopy.

Now, the prevalence of PID in India ranges from $1 \%$ to $17 \%$. Even subclinical PID is substantially associated with infertility and women with subclinical PID achieved 40\% less pregnancies compared to women without the same. Tubal factor infertility is the foremost reason of infertility among female patients, the majority of which is due to PID. ${ }^{(1,6)}$ In our study, we had 2 
cases of PID for whom recanalization of the tubal block was a failure.

The prevalence of genital tract $\mathrm{TB}$ in female ranges from $1 \%$ to $19 \%$ depending on the region. A study conducted in India found that more than $25 \%$ infertile patients (40 out of 150 ) had genital tuberculosis. $^{(1,5)}$ Luckily, we did not have genital tuberculosis in our study.

The fact that HSG has a considerably high falsenegative rateand a false-positive rate is a good argument to suggest that hysteroscopy represents an important complementary test in the work up of the infertile couple ${ }^{(2,3)}$ but when it is combined with hysteron-laparoscopy the accuracy is close to a $100 \%$. DHL is not only diagnostic but also therapeutic, hence it can be used to treat patients then and there. The chances of failure of treatment even though present, is significantly minimal. Hence it is safe to say, HSG when complemented with DHL, is a great diagnostic and therapeutic tool.

\section{References}

1. Chanu S, Pal R, Panda S, Singh S. Diagnostic hysterolaparoscopy for evaluation of infertility: Our experience in a tertiary Care Hospital. J Hum Reprod Sci. 2018;11:19-23.

2. Maiti GD, Lele P. Hysterosalpingography ( HSG ), hysteroscopy and laparoscopic evaluation of female genital tract of patient attending tertiary infertility centre and correlation of various modalities. Int $\mathbf{J}$ Reprod Contraception, Obstet Gynecol. 2018;7(4):1597-601.

3. Hourvitz A, Lédée N, Gervaise A, Fernandez H, Frydman R, Olivennes F. Should diagnostic hysteroscopy be a routine procedure during diagnostic laparoscopy in women with normal hysterosalpingography? Reprod Biomed Online [Internet]. Reproductive Healthcare Ltd, Duck End Farm, Dry Drayton,
Cambridge CB23 8DB, UK; 2002;4 (3):256-60. Available from: http://dx.doi.org/10.1016/S14726483(10)61815-9

4. Snowden EU, II JCJ, Dawood Y. Comparison of diagnostic accuracy of laparoscopy, hysteroscopy, and hysterosalpingography in evaluation of female infertility. Fertil Steril [Internet]. Elsevier Masson SAS; 1984;41(5):709-13. Available from: http://dx.doi.org/10.1016/S00150282(16)47836-2

5. Sarkar S, Gupta P. Socio-Demographic Correlates of Women's Infertility and Treatment Seeking Behavior in India. J Reprod Infertil. 2016;17(2):123-32.

6. Wadhwa L, Rani P, Bhatia P. Comparative Prospective Study of Hysterosalpingography and Hysteroscopy in Infertile Women. J Hum Reprod Sci. 2017;10(2):73-8. 